\title{
Autonomic Factors of Successful Foreign Language Acquisition by Students and Schoolchildren
}

\author{
DOI: $10.17691 / \mathrm{stm} 2019.11 .1 .21$
}

Received December 12, 2018

V.A. Demareva, PhD, Assistant, Department of Psychophysiology";

D.V. Bovykina, MSc Student, Department of Psychophysiology2;

Yu.A. Edeleva, Research Assistant, Department of German Studies²

${ }^{1}$ National Research Lobachevsky State University of Nizhny Novgorod, 23 Prospekt Gagarina, Nizhny Novgorod, 603950, Russia;

2Braunschweig University of Technology, 2 University Square, Braunschweig, 38106, Germany

The aim of the study was to identify autonomic factors of successful acquisition of a foreign language by students and schoolchildren and find the optimal modes of autonomic regulation of the learning processes.

Materials and Methods. 16 children in grade 4, 37 pupils in grades 5-11 studying at school with in-depth English language learning, and 10 second-year linguistics university students participated in the study.

The data on the functional state dynamics of the university students and schoolchildren during English lessons were collected using event-related telemetry technology, which continuously recorded the heart rate. A specially designed protocol and a standard 5-point grading scale were used to assess the language progress.

Results. The analysis of heart rate variability data in different contexts revealed a similarity in autonomic regulation modes for the schoolchildren and university students who studied English successfully. Consequently, similar functional states are typical for performing different language-related tasks. For all age groups, high activity of the autonomic nervous system was optimal for English learning. The difference was in the sympathetic and parasympathetic activity ratio: the contribution of the sympathetic circuit is more important for the university students, whereas the parasympathetic one - at school stage.

Conclusion. The study of a foreign language acquisition by the Russian students and schoolchildren showed that from the standpoint of psychophysiology, the main factor of success for the students was a high autonomic nervous system activity with a prominent dominance of the sympathetic activation. For the schoolchildren, a coordinated activation of both sympathetic and parasympathetic regulation modes was the most optimal state for language learning.

Key words: autonomic regulation; foreign language learning; optimal functional state; event-related telemetry of the heart rate; stress.

\section{Introduction}

The study of psychophysiological pre-requisites for optimal foreign language learning is one of the contemporary issues in modern cognitive science. It still remains unclear how autonomic nervous system modulates foreign language learning and to what extent heart rate variability (HRV) can determine the success in language-related tasks. HRV is a measure of neurocardiac function that reflects the correlation between heart rate and brain activity and the autonomic nervous system activity [1-3]. It is shown that heart activity affects not only autonomic regulatory centers. It also affects higher centers of the cortex involved in emotional and cognitive cycles, including thalamus, amygdala, and cortex. Through these pathways, heart activity can modulate various brain functions [1, 4-11], which provide successful foreign language acquisition.

Stress can also affect the process of learning. Scientifically, stress is best described by Selye, an
Austro-Canadian researcher [12, 13], whose ideas were further developed within the three-component theory of extremal states [14]. Within this framework, endogenous opioid system is a significant component of stress. It is activated from the first minutes of stress and its function is to limit excessive effects of sympathoadrenal system and hypothalamic-pituitary-adrenal axis [15].

The present study investigates the distribution of acute stress episodes that Russian-speaking schoolchildren and university students experienced during EFL-learning (English as a foreign language). Acute stress is the body's response at the first stage of stress ("anxiety"). The activation of sympathoadrenal system and endogenous opioid system is physiological marker of acute stress. Within this paper, a "stress episode" is defined as an autonomic manifestation of the interaction of neuroendocrine systems at the first stage of stress. A pattern that includes a drop in the total power of the HRV spectrum and an increase in the autonomic balance index ( $A B I-L F / H F)$ is regarded

Corresponding author: Valeriia A. Demareva, e-mail: kaleria.naz@gmail.com 
as an autonomic manifestation of the sympathoadrenal system and endogenous opioid system. A similar pattern is observed in the context of different loads (cognitive, motor, and emotional), which contain different stress factors [16, 17]. Stressogenicity is a number of stress episodes recorded during a specific activity context.

Data on optimal modes of autonomic regulation for successful mastering of a foreign language will provide the opportunity to create unique training courses of biological feedback to make the process highly effective.

\section{Materials and Methods}

Event-related telemetry. Heart rate was being continuously monitored using event-related telemetry technology [18] to collect data on the dynamics of the schoolchildren and students functional state during the EFL-class. The technology allowed us to monitor and analyze the dynamics of HRV during different events [16, 17]. Thus, ambient monitoring of the functional status of schoolchildren and university students during foreign language learning is possible irrespective of distance or mobility constraints.

A personalized analysis of the dynamics of autonomic regulation was carried out based on HRV spectral indices. Dynamic Fourier analysis with a window of $100 \mathrm{~s}$ and a step of $10 \mathrm{~s}$ was used to calculate the following indicators: the total power of the HRV spectrum - TP $\left(\mathrm{ms}^{2}\right)$, which is an index of the adaptation potential; power spectrum in the frequency range from 0.04 to $0.15 \mathrm{~Hz}-\mathrm{LF}\left(\mathrm{ms}^{2}\right)$, which is an index of sympathetic nervous system activity in modulating the heart rate; power spectrum in the frequency range from 0.15 to $0.4 \mathrm{~Hz}-\mathrm{HF}\left(\mathrm{ms}^{2}\right)$, which is an index of parasympathetic nervous system activity; the ratio of LF to HF is the $A B I$ characterizing the tension of regulatory systems [2].

The identification of specific indices of spectral HRV stress-response dynamics was based on the threecomponent theory of neurochemical mechanisms for the development of extreme states [19]. The detection of stress episodes was carried out based on the analysis of the dynamics of TP and LF/HF [20]. The duration and number of stress episodes during the monitoring session were recorded.

Eye tracking. Eye movements were recorded according to the method of video-oculography using the SMI Hi Speed 1250 installation (Germany). The text corpus from [21] was used as a stimulus material in English, the text corpus described in [22] was used in Russian stimuli.

Determining the success of English acquisition by the students and schoolchildren. A specially designed protocol was used to assess the "useful activity" at the EFL-class for the children in grade 4 and students [23]. Classroom interaction, as well as the use of the known and a new language material, were analyzed.

A standard academic 5-point grading scale was used to evaluate the progress in EFL-class in schoolchildren in grades 5-11.

Study design. Three groups were formed. Group 1 included 16 children in grade 4, group 2 comprised 37 pupils in grades 5-11 all studying at school with indepth English language learning. Group 3 consisted of 10 second-year students of the linguistics university specializing in "Theory and Methods of Teaching a Foreign Language".

Heart rate was continuously monitored during the EFL-class using event-related telemetry [18]. The progress in English learning was evaluated in each group. In group 3, eye movements were additionally recorded when students were reading the texts in Russian and English.

Data processing. Analysis of variance, cluster analysis, parametric (a posteriori analysis - Fisher criterion), and nonparametric (Mann-Whitney $U$ test) tests were performed to obtain statistical values.

\section{Results}

Age-related properties of the autonomic nervous system tonus before and after the EFL-class. To study functional state dynamics of Russian-speaking schoolchildren and university students during EFLlearning, the tonus of the autonomic nervous system before and after the class was analyzed taking into the account the age of the participants. Statistically significant results are described below.

All age groups showed the increase in the sympathetic system activation after the EFL-class. For beginner EFL-learners only, the central heart rate regulation contour was strengthened, the parasympathetic nervous system got activated, and the $\mathrm{ABI}$ was decreased after the EFL-class. Students demonstrated a significant increase in the $\mathrm{ABI}$ after the EFL-class. It turned out that LF and TP were significantly higher for schoolchildren in grades 10-11 than for those in grades 5-6 and 8-9. HF was significantly higher for schoolchildren in grades 10-11 than for those in grades 5-6. The $A B I$ (the ratio of LF/HF) was significantly higher for pupils in grades 10-11 than for those in grades 8-9.

So, at the initial stage of EFL-learning, the learning process leads to an increase in the power of the HRV spectrum and to a decrease in the tension of regulatory systems, and at more advanced stage the tension of regulatory systems is being increased.

The relationship of success in English acquisition and autonomic regulation modes. Cluster analysis was conducted in order to divide the schoolchildren of group 1 depending on their activity during the EFL-class. This group was divided into 2 clusters. Cluster 1 $(n=7)$ included children with a higher score on 5 of 12 parameters (U-test; $p<0.05$ ) than pupils from cluster 2 $(n=9)$. Children from cluster 1 were designated as "highperforming", and from cluster 2 as "low-performing".

When processing the results of the cluster analysis 
in group 2, EFL-class was evaluated by the teacher according to a standard academic 5-point grading scale. 4 schoolchildren received a rating of " 3 ", 21 pupils - "4", and 12 - " 5 ". For data processing, pupils were also divided into 2 clusters: those who got " 5 " ("high-performing") and those who got " 3 " and "4" ("low-performing").

For cluster analysis, group 3 was divided into 2 clusters depending on the students' activity during the EFL-class. Cluster 1 ("highperforming"; $n=5$ ) included students with a higher score on 7 of 12 parameters ( $U$ test; $\mathrm{p}<0.05$ ) than students from the cluster 2 ("lowperforming"; $n=5$ ).

For the elementary school pupils (group 1), successful English learning was established to be associated with a high total spectrum power of $\operatorname{HRV}(F(1,5716)=195.50 ; p<0.001)$ (see the Figure). A high power of both low-frequency ( $F \quad(1,5716)=25.907 ; p<0.001)$ and highfrequency components $(F(1,5716)=233.99$; $p<0.001)$ was also noted in this cluster. This indicates a coordinated increase in the activity of the sympathetic and parasympathetic autonomic regulation components.

In the successful pupils of the middle and high school (group 2), only a high-frequency component of the HRV spectrum appeared to be significantly higher. At the same time, all well-performing pupils demonstrated a lower tension of the regulatory system (LF/HF) during the lesson.

In the students of group 3, successful English learning was associated with a high power of the HRV spectrum at the expense of increased values in all of its constituents: sympathetic $(F \quad(1,4967)=108.84 ; p<0.001)$ and parasympathetic $(F \quad(1,4967)=171.03$; $p<0.001)$. The $A B I$ was higher for successful students $(F(1,4967)=27.43 ; p<0.001)$. This indicates a greater contribution of sympathetic regulation to English learning at the advanced stage. Also, successful mastering of EFL by students is associated with the absence of a change in the pupil diameter when working with texts in Russian and English. This indicates the similarity of the autonomic regulation regimes when performing linguistic tasks in the native and foreign languages with the latter being successfully mastered.

The effect of the class stress on EFL-learning progress. The distribution of stress episodes during the EFL-class was analyzed (Table 1). It was found that the time factor (the lesson phase) significantly affects the distribution of stress episodes during the entire period of schooling: the beginning of the lesson is the most stressful stage, fewer stress episodes were observed in the middle of the lesson than at the end of it (Fisher's
Table 1

Number of stress episodes per lesson stage

\begin{tabular}{lccccc}
\hline \multirow{2}{*}{ Stage } & \multicolumn{2}{c}{ Time $(\mathrm{min})$} & Grade 4 & Grades 5-11 & Students \\
\cline { 2 - 5 } & School & University & & & \\
Beginning & $0-15$ & $0-30$ & 6.1 & 4.9 & 6.9 \\
Middle & $15-30$ & $30-60$ & 3.1 & 2.8 & 7.1 \\
End & $30-45$ & $60-90$ & 3.6 & 3.9 & 8.8 \\
\hline
\end{tabular}

LSD test; $p<0.001)$. No such effect of the lesson stage could be observed for the university students.

Then the relationship between the number of stress episodes during the class and the quality of classroom performance in English was evaluated. No regularity was found for groups 2 and 3 . The analysis results for group 1 are given below.

K-means clustering was carried out to classify a 
sample of schoolchildren according to the stressrelated parameters (the number of stress episodes and their duration). As a result, the sample was divided into 2 clusters. Cluster 1 included 8 children with fewer stress episodes and their shorter duration. Cluster 2 included 8 pupils with a greater number of stress episodes and their increased length $(U$ test; $p<0.05)$. Cluster 1 was designated as a "low stress" cluster, cluster 2 - as a "high stress" cluster.

Then, the sample was re-clustered with the help of K-means in terms of "useful activity" during the class, and the results of previous clustering were used as a grouping variable. As a result, 3 clusters were distinguished. Cluster $1(n=5)$ included only schoolchildren with a low stress load at the lesson, and cluster $3(n=4)$ included only pupils with a high stress load during EFL-learning; cluster 2 consisted of 7 children.

Then schoolchildren's grades in English in clusters 1 (a low stress load) and 3 (a high stress load) were compared. Pupils with a low stress load during the lesson turned out to have significantly higher grades on three different language-related activities ( $U$ test; $p<0.05$ ) "interaction within a group", "accuracy using a known language material", and "use of known structures".

Therefore, low stress load is an indicator of a language progress during English learning.

\section{Discussion}

Specific HRV values were registered depending on the age group. It turned out that the activity of sympathetic and parasympathetic regulation circuits increases with age, which may indicate both agerelated properties of the autonomic nervous system (late myelination of tangential fibers of the cerebral cortex, which implies ion channel clustering in the nodes of Ranvier, an increase in excitability and nerve fiber lability), and the development of general language abilities that underlie the functioning in English as a foreign language.

All age groups evidenced an increase in the activation of the sympathetic nervous system after the EFL-class. Only at the initial stage of English learning, enhancement of the central heart rate regulation circuit, activation of the parasympathetic nervous system, and the decrease of the $\mathrm{ABI}$ after the English lesson have been noted.

Table 2

Functional state during classroom-based EFL-learning

\begin{tabular}{lcccc}
\hline \multirow{1}{*}{ Groups } & \multicolumn{4}{c}{ Optimal state markers } \\
\cline { 2 - 5 } & LF & HF & TP & ABI (LF/HF) \\
Primary school & High & High & High & Low \\
$\begin{array}{l}\text { Middle and high } \\
\text { school }\end{array}$ & High & High & High & Low \\
Students & High & High & High & High \\
\hline
\end{tabular}

The current study results demonstrate the changes in HRV during the EFL-class with schoolchildren studying in different school years. It was shown that the greatest number of stress episodes occurs at the beginning of the school lesson, while the middle of the lesson is the least stressful phase. The structure of a school lesson is regulated by the requirements of the Russian Federal State Educational Standard. This allows us to single out the most stressful activity types during an EFL-class with Russian-speaking schoolchildren. They are: lesson opening and directives; checking up the hometask.

Similar distribution of stress episodes was not found with university students, which may be related to the specificities of school and university classroom-based language teaching. The structure of a university English class is non-linear and implies a constant change of different types of activity. Since the measurements were carried out during different classes, their structure was different, which makes it difficult to determine stressinduced types of activity for students.

General features of spectral HRV indicators with high-performing schoolchildren and university students point to a high total power of the regulation spectrum as a result of an increase in the values of all its links (LF and $\mathrm{HF}$ ). For low-performing schoolers, the $\mathrm{ABI}$ was significantly higher, being indicative of greater intensity of parasympathetic regulation circuit activity in highperformers. This may be due to the activation of selective attention in successful pupils while performing linguistic tasks [2]. For university students, $A B I$ was higher in high-performers demonstrating a greater contribution of the sympathetic regulation. It has been shown that sympathetic activation can cause working memory improvement [24]. Presumably, when Russian university students learn English as part of their professional training, operational information processing plays a great role. On the one hand, a well-developed working memory determines a fast acquisition of a new material, on the other, the very fact of learning a foreign language may promote the improvement of the mnestic processes.

The analysis of HRV indicators in different contexts allowed us to conclude that autonomic regulation patterns are similar for the schoolchildren and university students who performed well at the EFL-class. Consequently, similar functional states are necessary for performing different linguistic tasks. In either age group, a high autonomic nervous system activity is optimal. However, university students and schoolchildren differ in the ratio of sympathetic and parasympathetic circuits: the contribution of the sympathetic activity is more important for students, and of the parasympathetic one - for schoolchildren (Table 2).

\section{Conclusion}

Thus, the study allows us to define the following main psychophysiological pre-requisites of successful EFL-learning by the Russian university students and 
schoolchildren. High autonomic nervous system activity with a pronounced dominance of sympathetic activation over parasympathetic one is a success factor for university students. The optimal state for schoolchildren studying a foreign language implies coordinated activation of both sympathetic and parasympathetic regulation modes.

Research funding. This work was supported by the Russian Foundation for Basic Research (grants No.18013-01225, 18-413-520006, 18-013-01169).

Conflict of interest. The authors have no conflicts of interest.

\section{References}

1. McCraty R., Atkinson M., Tomasino D., Bradley R.T. The coherent heart heart-brain interactions, psychophysiological coherence, and the emergence of system-wide order. Integral Review 2009; 5(2): 11-115.

2. McCraty R., Shaffer F. Heart rate variability: new perspectives on physiological mechanisms, assessment of self-regulatory capacity, and health risk. Glob Adv Health Med 2015; 4(1): 46-61, https://doi.org/10.7453/gahmj.2014.073.

3. Lacey J.I., Lacey B.C. Some autonomic-central nervous system interrelationships. In: Black P. (editor). Physiological correlates of emotion. Elsevier; 1970; 205-227, https://doi. org/10.1016/b978-0-12-102850-3.50016-5.

4. Bradley R.T., McCraty R., Atkinson M., Tomasino D., Daugherty A., Arguelles L. Emotion self-regulation, psychophysiological coherence, and test anxiety: results from an experiment using electrophysiological measures. Appl Psychophysiol Biofeedback 2010; 35(4): 261-283, https://doi. org/10.1007/s10484-010-9134-x.

5. McCraty R., Atkinson M., Bradley R.T. Electrophysiological evidence of intuition: Part 2. A systemwide process? J Altern Complement Med 2004; 10(2): 325236, https://doi.org/10.1089/107555304323062310.

6. Lane R.D., Reiman E.M., Aherm G.L., Thayer J.F. Activity in medial prefrontal cortex correlates with vagal component of heart rate variability during emotion. Brain and Cognition 2001; 47(1-2): 97-100.

7. Svensson T.H., Thorén P. Brain noradrenergic neurons in the locus coeruleus: inhibition by blood volume load through vagal afferents. Brain Res 1979; 172(1): 174-178, https://doi. org/10.1016/0006-8993(79)90908-9.

8. Schandry R., Montoya P. Event-related brain potentials and the processing of cardiac activity. Biol Psychol 1996; 42(12): 75-85, https://doi.org/10.1016/0301-0511(95)05147-3.

9. Montoya P., Schandry R., Müller A. Heartbeat evoked potentials (HEP): topography and influence of cardiac awareness and focus of attention. Electroencephalogr Clin Neurophysiol 1993; 88(3): 163-172, https://doi. org/10.1016/0168-5597(93)90001-6.

10. Zhang J.-X., Harper R.M., Frysinger R.C. Respiratory modulation of neuronal discharge in the central nucleus of the amygdala during sleep and waking state. Exp Neurol 1986; 91(1): 193-207, https://doi.org/10.1016/0014-4886(86) 90037-3.
11. Umetani K., Singer D.H., McCraty R., Atkinson M. Twenty-four hour time domain heart rate variability and heart rate: relations to age and gender over nine decades. J Am Coll Cardiol 1998; 31(3): 593-601, https://doi.org/10.1016/s07351097(97)00554-8.

12. Selye H. The physiology and pathology of exposure to stress. Montreal: Acta Inc.; 1950.

13. Selye H. History of the stress concept. In: L. Goldberger, Breznitz S. (editors). Handbook of stress: theoretical and clinical aspects. New York: Free Press; 1993; p. 7-17.

14. Parin S.B. Humans and animals in extreme situations: neurochemistry mechanisms, evolutionary aspect. Vestnik NGU. Seriya: Psikhologiya 2008; 2(2): 118-135.

15. Parin S.B. Neurochemical and psychophysiological mechanisms of stress and shock. Vestnik Nizhegorodskogo gosudarstvennogo universiteta im. N.I. Lobachevskogo 2001; 1: 20-28.

16. Polevaya S.A., Nekrasova M.M., Runova E.V., Bakhchina A.V., Gorbunova N.A., Bryantseva N.V., Kozhevnikov V.V., Shishalov I.S., Parin S.B. Discrete monitoring and telemetry of heart beat during intensive work on the computer for the assessment and prophylaxis of fatigue and stress. Medicinskij al'manah 2013; 2(26): 151-155.

17. Runova E.V., Grigoreva V.N., Bakhchina A.V., Parin S.B., Shishalov I.S., Kozhevnikov V.V., Nekrasova M.M., Karatushina D.I., Grigoreva K.A., Polevaya S.A. Vegetative correlates of conscious representation of emotional stress. Sovremennye tekhnologii v meditsine 2013; 5(4): 69-77.

18. Polevaia S., Parin S., Eremin E., Bulanov N., Chernova M., Parina I., Chikov M., Chernigovskaya T. Eventrelated telemetry (ERT) technology for study of cognitive functions. Int J Psychophysiol 2016; 108: 87-88, https://doi. org/10.1016/j.ijpsycho.2016.07.274.

19. Parin S.B., Yakhno V.G., Tsverov A.V., Polevaya S.A. Psychophysiological and neurochemical mechanisms of stress and shock: experiment and model. Vestnik Nizhegorodskogo gosudarstvennogo universiteta im. N.I. Lobachevskogo 2007; 4: 190-196.

20. Parin S.B., Vetyugov V.V., Bakhchina A.V., Polevaya S.A. The role of the endogenous opioid system in the control of heart rate variability under cognitive loads of various levels. Sovremennye tekhnologii v meditsine 2014; 6(4): 116-126.

21. Liversedge S.P., Drieghe D., Li X., Yan G., Bai X., Hyönä J. Universality in eye movements and reading: a trilingual investigation. Cognition 2016; 147: 1-20, https:/ldol. org/10.1016/j.cognition.2015.10.013.

22. Demareva V.A., Polevaya A.V., Kushina N.V. The effect of language density on eye movements during silent reading in Russian and English. Vestnik psikhofiziologii 2018; 4: 140-145.

23. Demareva V.A., Polevaya S.A. Heart rate variability as a physiological criterion for assessing the impact of stress loads on the success of English language learning by primary schoolchildren. Vestnik psikhofiziologii 2017: 1: $24-31$.

24. Ramsey A., Rolnick K., Smith R., Weng Ch., Li Y., Lokuta A. Activation of the human sympathetic nervous system: effects on memory performance. Journal of Advanced Student Science 2012; 1. URL. Jass.neuro.wisc.edu/2012/01/ Lab\%20603\%20Group\%2010\%20Final\%20Submission\%20 Ramsey,\%20Rolnick, \%20Smith.pdf. 